\title{
Minimization of losses in a distribution system with network reconfiguration, distributed generation and D-STATCOM
}

\author{
Surender Reddy Salkuti* \\ Department of Railroad and Electrical Engineering, Woosong University, Daejeon-34606, Republic of Korea
}

Received: 29-August-2021; Revised: 16-December-2021; Accepted: 17-December-2021

(C)2021 Surender Reddy Salkuti. This is an open access article distributed under the Creative Commons Attribution (CC BY) License, which permits unrestricted use, distribution, and reproduction in any medium, provided the original work is properly cited.

\begin{abstract}
The increasing power demand in the distribution networks is the major driving force for the power industry to move towards the technological revolution, power industry deregulation, and privatization. This paper proposes an approach to reduce power losses in the Radial Distribution System (RDS) employing Network Reconfiguration (NR) and Distributed Generation (DG). This work proposes different combinations of NR, DG, and Distribution Static Compensator (DSTATCOM) integrations to handle the technical, economic, environmental, and reliability concerns of RDSs. Here, the Differential Evolution Algorithm (DEA) is used for solving the proposed problem. Simulations are performed on IEEE69 bus RDS. The obtained results reveal that by simultaneous allocation of DG and D-STATCOM units along with NR has resulted in an $82.92 \%$ reduction in power losses when compared to the system with base case configuration. And also, by applying the proposed approach the minimum voltage in the system has been increased to 0.9805 p.u. from 0.9085 p.u.
\end{abstract}

\section{Keywords}

Network reconfiguration, Distributed generation, Power loss, D-STATCOM, Distribution system, Differential evolution.

\section{Introduction}

In recent years, it can be observed that there is a requirement to increase the power generation capacity to meet the increased load demand. One needs to meet this increasing demand economically and reliably. The investment in the modification or up-gradation of the existing network, is practically a hard challenge because of strict economic and environmental constraints. This causes the distribution networks to operate closer to their voltage stability limits, which makes the operation and control of distribution systems further complicated [1-3]. The focus of present power utilities is on prolonged utilization of existing infrastructure with better planning incorporating smart technologies. The present focus of power utilities is on prolonged utilization of existing infrastructure with better planning incorporating smart technologies. The active power loss minimization, minimization of operational and investment cost, minimization of environmental effects, and enhancement of reliability are considered as essential planning objectives while maintaining and upgrading the existing power system infrastructure, particularly in overburdened networks.

*Author for correspondence 1557
Some of the established techniques to handle distribution systems under such a competitive scenario include Network Reconfiguration (NR), Distributed Generation (DG) allocation, and the use of Flexible Alternating Current Transmission System (FACTS) devices, and the combinations of these approaches $[4,5]$. Hence, the existing distribution system needs to be optimized in order to ensure reliable, economic, and safe electric power to the customers. The DG units could be either renewable such as solar Photovoltaic (PV) power, wind power, biomass, solar thermal system, small-scale hydropower, or non-renewable energy sources such as diesel generators, etc.

As the demand for electricity is growing continuously due to an increase in the population, urbanization, and industrialization, etc. To enhance the economic efficiency in such conditions, the power sectors have adopted remarkable modifications towards decentralization. Literature review reveals that very few researchers have done NR simultaneously with DG and Distribution Static Compensator (DSTATCOM) placement and sizing. It is observed from the literature that simultaneous $\mathrm{NR}$ in the presence of DG and D-STATCOM for the minimization of loss and enhancement of voltage 
profile has been considered by only a few researchers [6-8]. This necessitates the development of multiobjective methods with the inclusion of load ability and reliability objectives, which are very relevant for overburdened networks and are susceptible to frequent voltage instability issues. In order to reduce the computational burden and complexity of the problem with those objectives, it is required to develop fast and robust meta-heuristic-based optimization algorithms. Many new metaheuristic techniques are often successfully handled those highly constrained, mixed-integer, non-linear distribution system optimization problems, however, finding a near-global solution is still a challenging task for the researchers.

The recent trend in distribution system planning includes simultaneous NR, DG, and D-STATCOM allocation which has brought in many benefits such as power loss reduction, reliability enhancement, economic savings, and environmental pollution optimization $[9,10]$. However, owing to its largescale, non-linear and complex nature, it is very challenging to get an effective solution technique. The reported works from the literature are categorized into heuristic and Artificial Intelligence (AI) based techniques. Heuristic techniques are divided into two categories, i.e., trial and error-based methods and meta-heuristic methods. However, the meta-heuristic-based methods are very popular and effective in handling combinatorial, constrained, and high dimensional problems like simultaneous NR, DG, and D-STATCOM allocation. In this paper, the Differential Evolution Algorithm (DEA) is used for solving the proposed simultaneous optimization problem of the Radial Distribution System (RDS).

In recent years power utilities are facing major challenges owing to exponential load growths, transmission line contingencies, and power system blackouts. This brings the distribution systems more closely to their voltage stability boundaries, which makes the control and operation of these systems more complicated. To meet the growing energy demand, distribution systems need to be upgraded, which is practically a hard challenge because of strict economic and environmental constraints. In such stressed situations, NR is proven to be a viable tool to mitigate such issues effectively. In recent years, optimal DG and D-STATCOM allocation is also chosen as a viable option to solve this issue. However, NR, DG, and D-STATCOM allocation cannot be random as it may result in inefficient performance and unintended operation of the system.
Moreover, it is important to maintain the radial and connected structure of the system after reconfiguration as well as to determine the appropriate position and size of DG units along with the fulfillment of the objectives in an economical, reliable, and environmentally friendly way without violating the system operating constraints.

\section{Literature review}

Various advanced computational approaches have been developed and implemented in the literature, including conventional, intelligent, and hybrid approaches considering the primary concern of NR, DG, and D-STATCOM planners in the presence of different distribution systems, objectives, operating constraints, and load variation. Among them, evolutionary/ meta-heuristic optimization methods are getting more prioritized in the multi-objective environment. Several distribution network enhancements are based on simultaneous NR, DG, and D-STATCOM allocation. However, owing to its large-scale, non-linear and complex nature, it is very challenging to get a solution technique.

Optimal Network Reconfiguration (ONR) is an approach that will be used to enhance voltages in the system and to minimize the losses in the power distribution networks, and it is a huge combinational search space optimization (i.e., mixed-integer nonlinear) problem [11].

A water cycle algorithm has been proposed in [12] for solving the optimal sizing and sitting of DG units. Zhan et al. [13] proposed a methodology to find the ONR by considering the uncertain nature of load demand and solar PV output. A two-stage robust optimization approach for solving the ONR with load demand uncertainty has been proposed in [14, 15].

A combination of Ant Colony Optimization (ACO) and fuzzy multi-objective approach is proposed in [15] for solving the simultaneous ONR and allocation of D-STATCOM and solar PV arrays.

Tolabi et al. [16] proposed a heuristic technique based on convex relaxation of AC Optimal Power Flow (OPF) for solving the ONR problem. An exhaustive power flow has been carried out by solving the ONR problem with the aim of loss minimization along with the voltage profile improvement in the presence of shunt capacitors in the RDS [17]. 
Magadum and Kulkarni [18] proposed simultaneous use of ONR and optimal allocation of shunt capacitors and DG units by considering the multiple conflicting objectives, i.e., minimization of power loss in the RDS, voltage stability enhancement, and reduction in line loading. An approach for solving the ONR problem using the Supporting Hyperplanes algorithm and Mixed-Integer Linear Programming (MILP) is solved in [19] and it determines the on/off status of switches and optimal placement of shunt capacitors and DG for power loss minimization. An OPF based heuristic methodology for ONR with continuous functions to model open/close switch has been proposed in [20]. The proposed technique starts by closing all the switches. Then, based on the heuristic technique obtained from the ONR solution the switch that candidate to be open to break the next loop is selected. This procedure is repeated until all the loops are broken and a radial configuration is obtained.

From the above review, it is observed that various techniques have been proposed for NR, DG, and DSTATCOM by considering the various objectives. However, there is a requirement for solving the optimal distribution system problem by considering NR, DG units, and D-STATCOM simultaneously. In this paper, the DEA is used for solving the proposed problem with loss minimization objectives. This paper develops different combinations of NR, DG, and D-STATCOM allocation to strengthen the efficiency of distribution systems based on power loss minimization and voltage profile enhancement, as these are the two major issues in the recent competitive power scenario. This paper proposed the optimal planning of smart distribution networks with DG and D-STATCOM allocation, and also emphasized the future research directions.

\section{Methods}

\subsection{Distribution load flow (DLF)}

This section describes the mathematical equations in the load flow formulation and the necessary steps to obtain the objective of the work. Most of the distribution system load flow techniques are predominantly based on backward forward sweep methodology, and it is cleared from the existing research work. In this paper, the load flow proposed in reference [21] is used. In this method, the backward propagation method is used to calculate the line currents by using Equation 1 .

$I_{j}=\left(\frac{s_{j}}{V_{j}}\right)^{*} \quad i=1,2,3, \ldots, N_{B}$
Where $V_{j}$ and $S_{j}$ are the bus voltage and complex load demand at bus j. $N_{B}$ is the number of buses. The forward propagation method is used to determine the voltage at each bus with the current in each line is held constant to the value obtained in the backward step. The voltage at the bus $(j+1)$ is calculated by using the forward propagation as [22, 23] (Equation 2).

$V_{j+1}=V_{j}-I_{j}\left(R_{k}+j X_{k}\right)$

The load flow is converged, if the voltage difference between two consecutive iterations is less than the specified tolerance $(\varepsilon)$ value, and it can be expressed as [24] (Equation 3).

$\max \left(\left|V_{j}^{t}\right|-\left|V_{j}^{t-1}\right|\right)<\varepsilon$

where $V_{j}^{t}$ and $V_{j}^{t-1}$ are the voltages at bus $\mathrm{j}$ in $\mathrm{t}^{\text {th }}$ and $(\mathrm{t}-1)^{\text {th }}$ iterations, respectively

\subsection{Modeling of RDS}

The Single Line Diagram (SLD) of RDS is depicted in Figure 1. The real and reactive power losses in a $\mathrm{k}^{\text {th }}$ line between the buses $\mathrm{j}$ and $(\mathrm{j}+1)$ can be expressed as $[25,26]$ (Equation 4 and 5).

$$
\begin{aligned}
& P_{(j, j+1)}^{l o s s}=R_{k}\left(\frac{P_{k}^{2}+Q_{k}^{2}}{\left|V_{j}\right|^{2}}\right) \\
& Q_{(j, j+1)}^{l o s s}=X_{k}\left(\frac{P_{k}^{2}+Q_{k}^{2}}{\left|V_{j}\right|^{2}}\right)
\end{aligned}
$$

Where $R_{k}$ and $X_{k}$ are resistance and reactance of a branch connected between the nodes $j$ and $(j+1) . I_{j}$ is the line current in the $\mathrm{k}^{\text {th }}$ line.

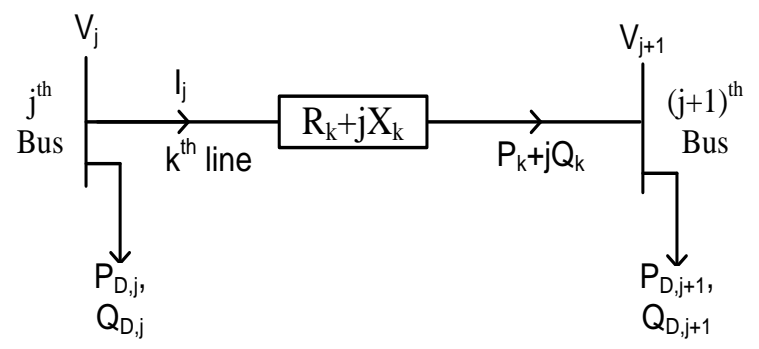

Figure 1 SLD of RDS

Total Active Power Loss (TPL) and Total Reactive Power Loss (TQL) of the entire RDS are expressed as Equation 6 and 7.

$$
\begin{aligned}
& \mathrm{TPL}=\sum_{k=1}^{N_{l}} P_{(j, j+1)}^{\text {loss }} \\
& \mathrm{TQL}=\sum_{k=1}^{N_{l}} Q_{(j, j+1)}^{\text {loss }}
\end{aligned}
$$




\subsection{Modeling of D-STATCOM}

Figure 2 depicts the D-STATCOM installed at a bus $(j+1)$ of RDS. D-STATCOM is a power electronicbased shunt connected distribution Flexible Alternating Current Transmission System (FACTS)

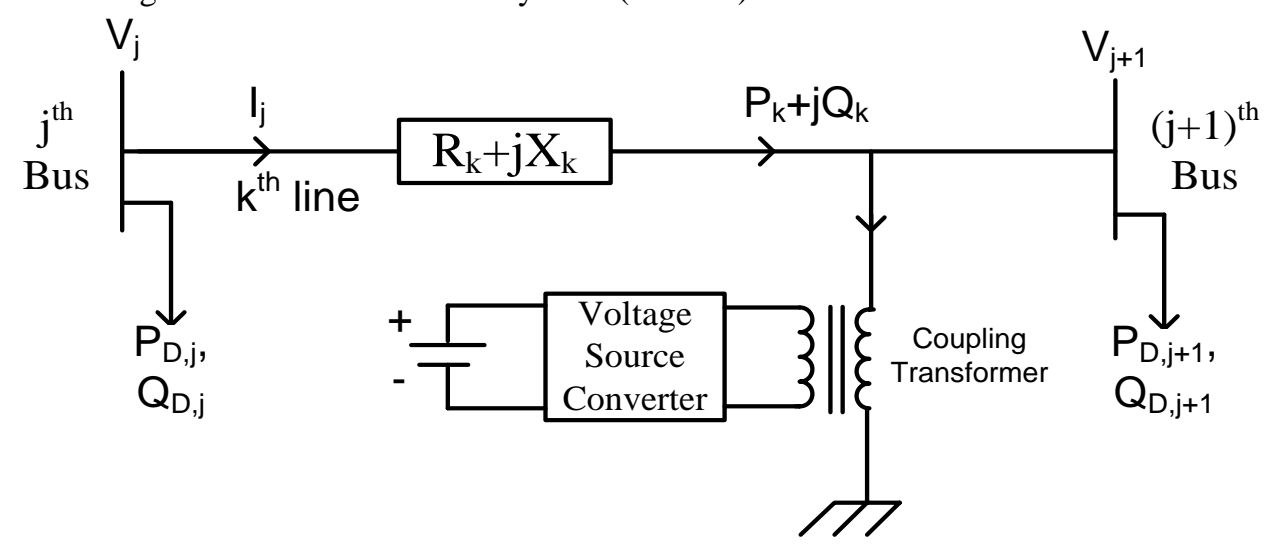

device used for the compensation of reactive power [27, 28]. This D-STATCOM consists of a coupling transformer and Voltage Source Converter (VSC).

Figure 2 Modeling of D-STATCOM installed at the bus $(j+1)$ of RDS

\subsection{Objective function and constraints}

The main aim of this work is to minimize TPL in the system [29]. Mathematically, it can be expressed as Equation 8.

Minimize,

$\sum_{k=1}^{N_{B}} P_{k}^{\text {loss }}$

\section{Subjected to the following constraints.}

3.4.1Equality constraints

This is the power balance constraint, which states that power output from the grid and DG must be equal to power demand by the consumers and power losses in the lines [30, 31]. This constraint can be expressed as Equation 9.

$P_{G}^{\text {Grid }}+\sum_{i=1}^{N_{D G}} P_{D G, i}=\sum_{j=1}^{N_{B}} P_{D, j}+\sum_{k=1}^{N_{l}} P_{k}^{\text {loss }}$

$P_{G}^{G r i d}$ and $P_{D G, i}$ are the active power outputs/power generations from the grid and $\mathrm{i}^{\text {th }} \mathrm{DG}$ unit [32]. $P_{G, i}$ is the power generation at bus $\mathrm{i}$ and $P_{D, i}$ is the power demand of loads connected at bus i. Power balance equation at a particular bus $i$ is given by Equation 10 . $P_{G, i}=P_{D G, i}+P_{D, i}$

In similar lines, the reactive power balance equation is given by [33] (Equation 11).

$Q_{G}^{G r i d}+\sum_{i=1}^{N_{D G}} Q_{D G, i}+Q_{D-S T A T C O M}=\sum_{j=1}^{N_{B}} Q_{D, j}+$ $\sum_{k=1}^{N_{l}} Q_{k}^{\text {loss }}$

Where $Q_{G}^{G r i d}$ is reactive power output/generated from the grid, $Q_{D G, i}$ is reactive power generated from the $\mathrm{i}^{\text {th }}$ DG unit, and $Q_{D-S T A T C O M}$ is reactive power output from D-STATCOM [34]. $N_{D G}$ and $N_{l}$ are the number of DG units and lines/branches.

3.4.2Inequality constraints

The limits on active and reactive power outputs from the DG units can be expressed as [35] (Equation 12 and 13).

$P_{D G, i}^{\min } \leq P_{D G, i} \leq P_{D G, i}^{\max }$
$Q_{D G, i}^{\min } \leq Q_{D G, i} \leq Q_{D G, i}^{\max }$

Line current constraints: The current flow in each line $\left(I_{l}\right)$ is limited due to its maximum current carrying capacity $\left(I_{l}^{\max }\right)$, and mathematically, it is expressed by [36, 37] (Equation 14).

$\left|I_{l}\right| \leq I_{l}^{\max }$

Constraints on bus voltages: Node/bus voltage of the system $\left(V_{i}\right)$ is limited by minimum and maximum limits, and it can be expressed as [38, 39] (Equation 15).

$V_{i}^{\min } \leq V_{i} \leq V_{i}^{\max }$

\subsection{Solution methodology}

Though the classic heuristic algorithms are more accurate they do not guarantee global optimal solutions for the systems with higher complexity. Therefore, during the last three decades, much research interest has been concentrated on the metaheuristic algorithms to resolve various problems associated with the distribution systems [40, 41]. Figure 3 depicts the solution methodology of the proposed optimization problem using the DEA. From this figure, it can be seen that the first step involved the load flow and calculating the power losses. 
Fitness function is determined for the corresponding DEA solution. Then the stopping criterion is checked $[42,43]$, if it is satisfied then print the optimum results, otherwise, apply mutation, crossover, and selection operators until the stopping criteria are met.

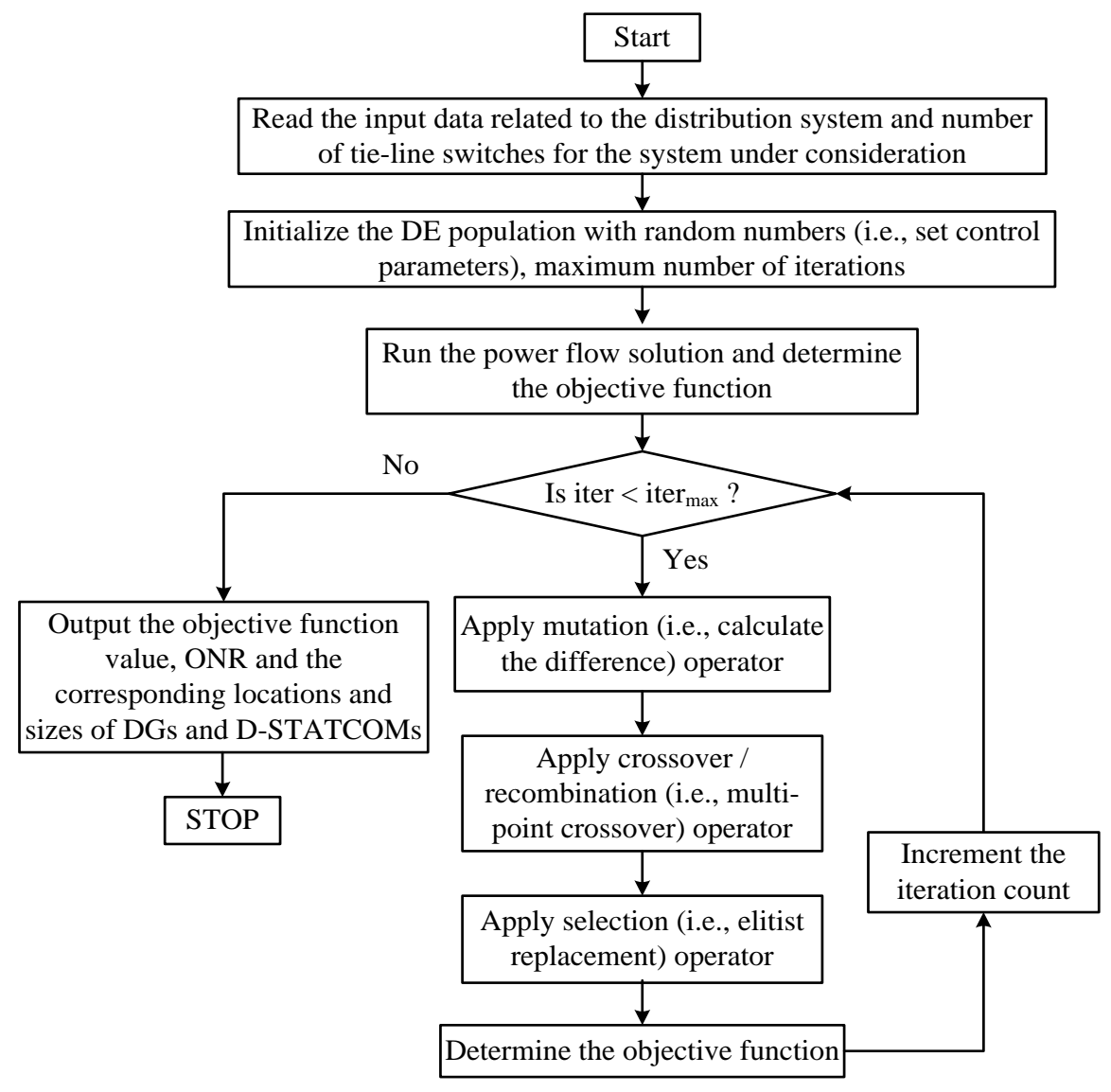

Figure 3 Solution methodology of the proposed optimization problem

\section{Results}

To show the effectiveness and to validate the obtained results using the proposed solution methodology, the IEEE 69 bus RDS are selected in this paper. The test system data, i.e., load demand, lines, and tie-lines are taken from [44]. The active and reactive power demands of this test system are $3,802 \mathrm{~kW}$ and 2,694 $\mathrm{kVAr}$, respectively. In this test system, the base case active power loss is $225.041 \mathrm{~kW}$. This system has 68 lines (1-68), i.e., sectionalizing switches (normally closed) and 5 tielines (69-73), i.e., tie-line switches (normally open), and they are shown in Figure 4. Here, the DLF is performed by considering the base voltage of 12.66 $\mathrm{kV}$ and the base MVA of 100. In this test system, the base case power loss obtained is $225.04 \mathrm{~kW}$. Based on the several works from the literature, in the present work, it is assumed that a maximum of $3 \mathrm{DG}$ is incorporated in this test system, and the maximum capacity of each DG unit is $2 \mathrm{MW}$. Inside the DEA, it is considered that the DE population size is 50 and the maximum number of iterations is 200. In this paper, all the programs are developed in MATLAB and they are implemented on a PC with an Intel Core i7 processor, $8 \mathrm{~GB}$ RAM, and $2.40 \mathrm{GHz}$ base frequency.

In this work, 6 simulation studies are performed, and they are:

- Case 1: Without any optimization (base case)

- Case 2: Operation of RDS with only NR

- Case 3: Operation of RDS with only DG allocation

- Case 4: Operation of RDS with both NR and DG allocation

- Case 5: Operation of RDS with both NR and DSTATCOM

- Case 6: Operation of RDS with simultaneous NR, DG allocation and D-STATCOM 


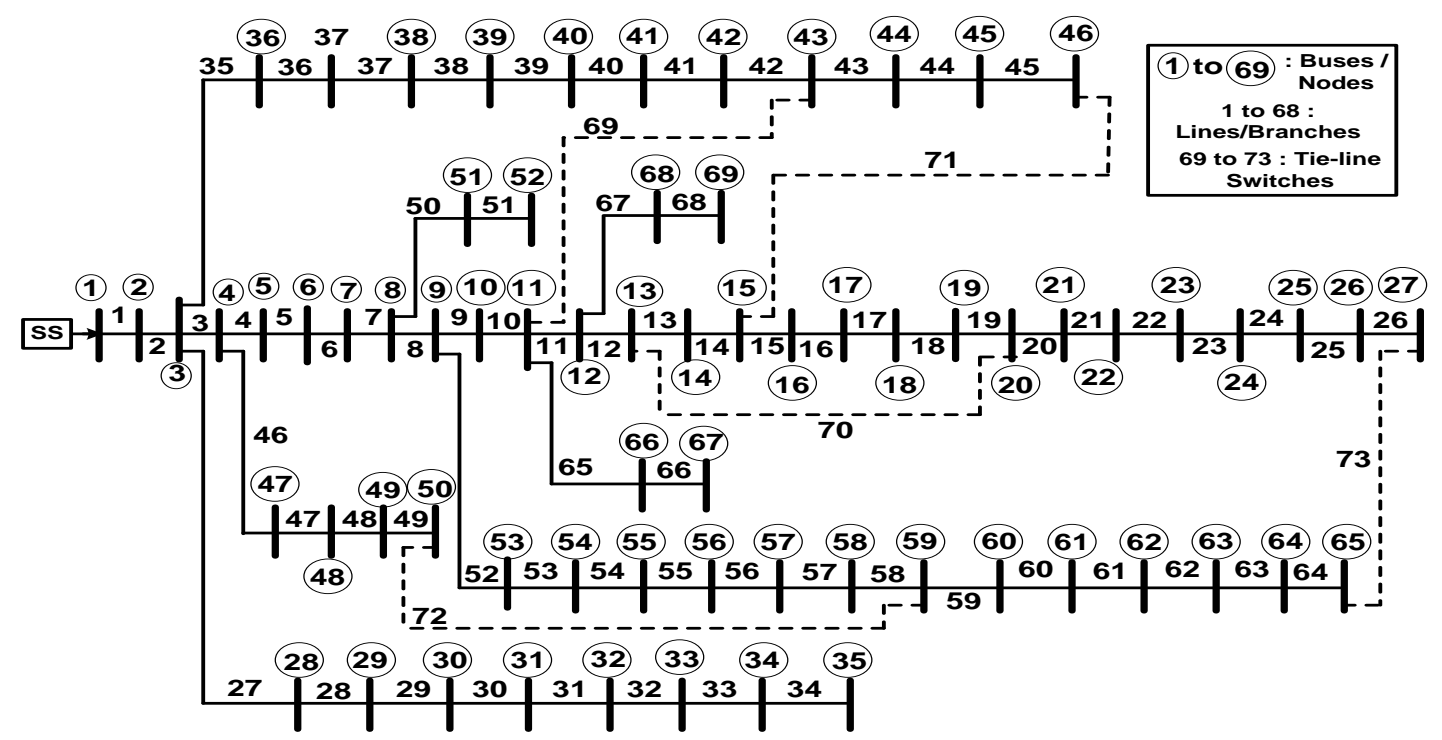

Figure 4 SLD of IEEE 69 bus before the NR

\subsection{Results for case 1}

In this paper, case 1 refers to the base case, i.e., without NR, DG, and D-STATCOM allocation. In this case, lines 1 to 68 are closed, and the switches 69 to 73 are opened. Power losses obtained in this case are $225.041 \mathrm{~kW}$. In this case, the minimum voltage is obtained at bus number 65 and its value 0.9085 p.u., and they are presented in Table 1.

Table 1 Simulation results for cases 1, 2, and 3

\begin{tabular}{|c|c|c|c|}
\hline & Case 1 & Case 2 & Case 3 \\
\hline Opened switches & $69,70,71,72,73$ & $69,70,14,56,61$ & $69,70,71,72,73$ \\
\hline DG size and location & $\begin{array}{ll}---- \\
\end{array}$ & $\begin{array}{ll}---- \\
\end{array}$ & $\begin{array}{l}483 \mathrm{~kW} \text { at bus } 10 \\
351 \mathrm{~kW} \text { at bus } 16 \\
1486 \mathrm{~kW} \text { at bus } 60\end{array}$ \\
\hline Total capacity of DG units & ----- & ----- & $2320 \mathrm{~kW}$ \\
\hline $\begin{array}{l}\text { Minimum voltage in the system } \\
\text { (in p.u.) }\end{array}$ & 0.9085 p.u. at bus 65 & 0.9419 p.u. at bus 62 & 0.9637 p.u. at bus 65 \\
\hline Power losses (in kW) & $225.041 \mathrm{~kW}$ & $99.265 \mathrm{~kW}$ & $82.611 \mathrm{~kW}$ \\
\hline $\begin{array}{l}\text { Percentage reduction in power } \\
\text { losses }\end{array}$ & $\begin{array}{ll}---- \\
\end{array}$ & 55.89 & 63.29 \\
\hline
\end{tabular}

\subsection{Results for case 2}

As mentioned earlier, in this case, the optimization on 69 bus RDS is performed by considering only the NR. After the NR, lines 69, 70, 14, 56, and 61 are opened, and the system configuration has been depicted in Figure 5. Simulation results obtained in this case are reported in Table 1. The minimum loss obtained in this case is $99.265 \mathrm{~kW}$, which is $55.89 \%$ less when compared to losses obtained in Case 1. In this case, the minimum voltage is obtained at bus number 62, and its value is 0.9419 p.u.

\subsection{Results for case 3}

In this case, the simulations are performed by considering the allocation of DG units. The solution 1562 methodology presented in Figure 3 is used for the implementation of the proposed optimization problem. As this case doesn't consider the NR, lines 69 to 73 are opened. Here, 3 DG units are installed at the buses 10, 16, and 60, and their capacities are 483 $\mathrm{kW}, 351 \mathrm{~kW}$, and $1486 \mathrm{~kW}$, respectively. The total capacity of these three DG units is $2320 \mathrm{~kW}$. The minimum loss obtained in this case is $82.611 \mathrm{~kW}$, which is $63.29 \%$ less when compared to the power losses of Case 1. In this case, the minimum voltage is obtained at bus number 62, and its value is 0.9419 p.u.

A complete list of abbreviations is shown in Appendix I. 


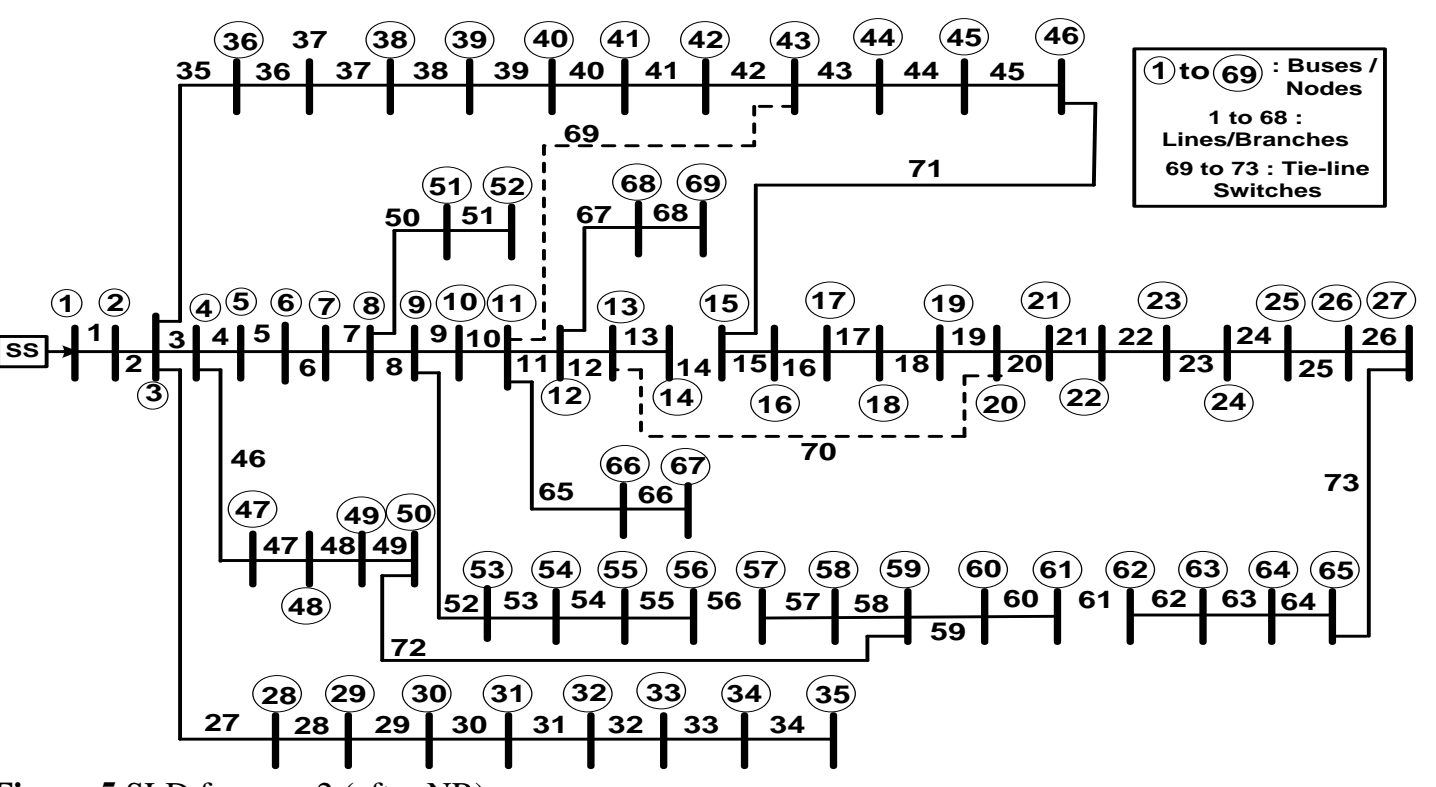

Figure 5 SLD for case 2 (after NR)

\subsection{Results for case 4}

In this case, the simulations are performed by considering the allocation of DG units and NR simultaneously. Here, the solution methodology presented in Figure 3 is used. The results obtained for this case are reported in Table 2. In this case, NR gives the lines $69,70,14,55$, and 62 are opened. Here, 3 DG units are installed at the buses 11, 27, and 61 , and their capacities are $492 \mathrm{~kW}, 506 \mathrm{~kW}$, and $1490 \mathrm{~kW}$, respectively. The total capacity of these three DG units is $2488 \mathrm{~kW}$. The minimum loss obtained in this case is $41.605 \mathrm{~kW}$, which is $81.51 \%$ less compared to the power losses of Case 1 . In this case, the minimum voltage is obtained at bus number 64 and its value 0.9790 p.u.

\subsection{Results for case 5}

In this case, the simulations are performed by considering the allocation of D-STATCOM and NR simultaneously. The results obtained for this case are reported in Table 2. In this case, NR gives the lines 69, 71, 15, 54, and 61 are opened. Here, one DSTATCOM has been installed at bus number 62 and its value is $984 \mathrm{kVAr}$. The minimum loss obtained in this case is $80.085 \mathrm{~kW}$, which is $64.41 \%$ less when compared to the power losses of Case 1. In this case, the minimum voltage is obtained at bus number 62 and its value 0.9532 p.u.

\subsection{Results for case 6}

In this case, the simulations are performed by considering the allocation of DG units, DSTATCOM, and NR simultaneously. Here, the solution methodology presented in Figure 3 is used. The results obtained for this case are reported in Table 2. In this case, NR gives the lines 69, 13, 21, 55 , and 64 are opened. Here, 3 DG units are installed at the buses 16, 50, and 61 and their capacities are $488 \mathrm{~kW}, 510 \mathrm{~kW}$, and $1459 \mathrm{~kW}$, respectively. One DSTATCOM is installed bus number 65 and its value is $1105 \mathrm{kVAr}$. Figure 6 depicts the optimal configuration of the IEEE 69 bus RDS system for Case 6. The minimum loss obtained in this case is $38.429 \mathrm{~kW}$, which is $82.92 \%$ less compared to the power losses of Case 1. In this case, the minimum voltage is obtained at bus number 65 and its value 0.9805 p.u.

Table 2 Simulation results for cases 4,5 , and 6

\begin{tabular}{llll}
\hline & Case 4 & Case 5 & Case 6 \\
\hline Opened switches & $69,70,14,55,62$ & $69,71,15,54,61$ & $69,13,21,55,64$ \\
\hline DG size and location & $492 \mathrm{~kW}$ at bus 11 & ---- & $488 \mathrm{~kW}$ at bus 16 \\
& $506 \mathrm{~kW}$ at bus 27 & & $510 \mathrm{~kW}$ at bus 50 \\
& $1490 \mathrm{~kW}$ at bus 61 & & $1459 \mathrm{~kW}$ at bus 61 \\
\hline Total capacity of DG units & $2488 \mathrm{~kW}$ & ----- & $1105 \mathrm{kVAr}$ at bus 62 \\
\hline $\begin{array}{l}\text { D-STATCOM size and location (in } \\
\text { kVAr) }\end{array}$ & ---- & $984 \mathrm{kVAr}$ at bus 62 & \\
\hline
\end{tabular}




\begin{tabular}{llll}
\hline & Case 4 & Case 5 & Case 6 \\
\hline $\begin{array}{l}\text { Minimum voltage in the system (in } \\
\text { p.u.) }\end{array}$ & 0.9790 p.u. at bus 64 & 0.9532 p.u. at bus 65 & 0.9805 p.u. at bus 65 \\
\hline Power loss (in $\mathrm{kW}$ ) & $41.605 \mathrm{~kW}$ & $80.085 \mathrm{~kW}$ & $38.429 \mathrm{~kW}$ \\
\hline Percentage reduction in power loss & $81.51 \%$ & $64.41 \%$ & $82.92 \%$ \\
\hline
\end{tabular}

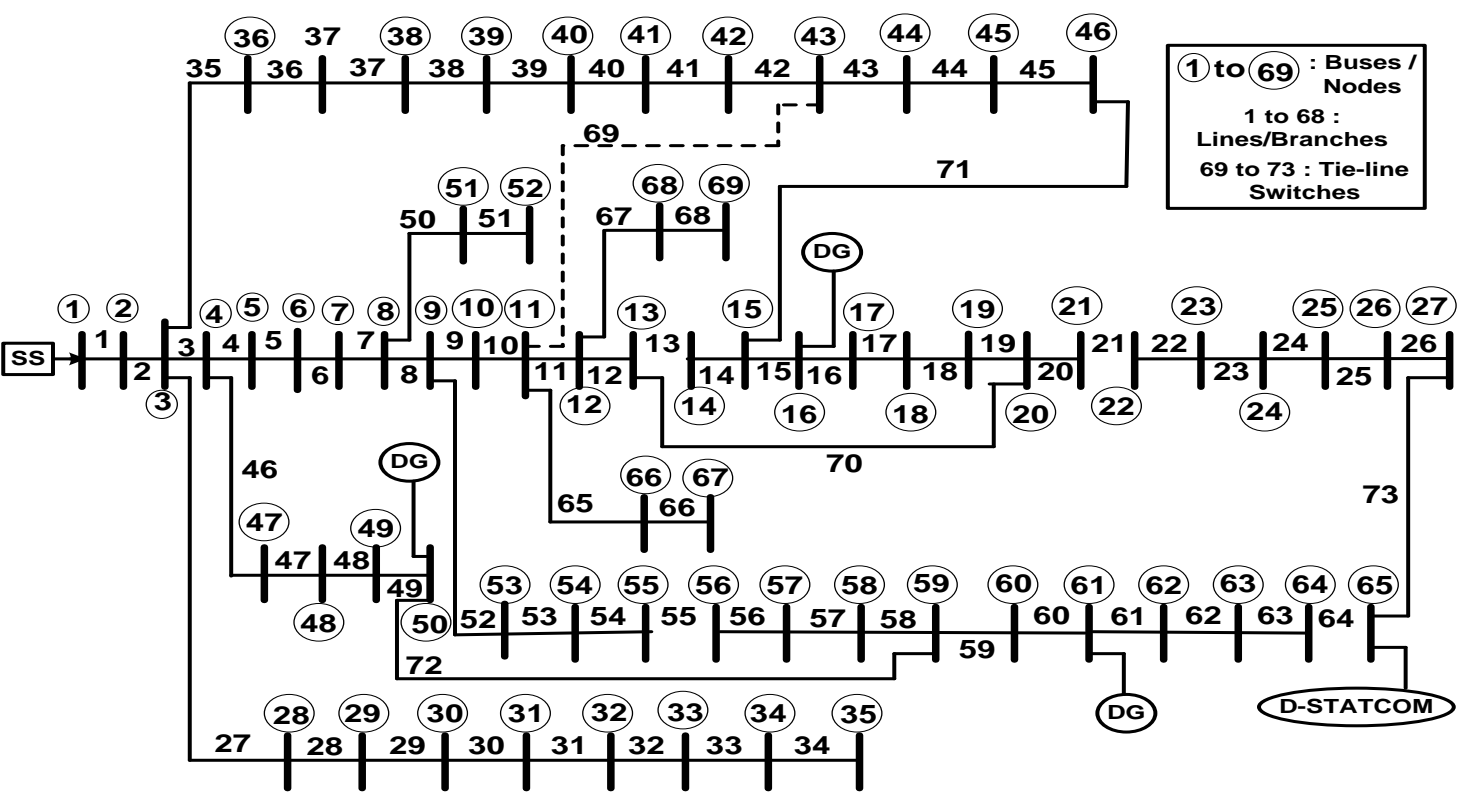

Figure 6 Optimal configuration of IEEE 69 bus system for Case 6

\section{Discussion}

This paper addressed the various challenges of distribution network planning in the present deregulated environment with different scenarios of NR, DG, and D-STATCOM allocation. As mentioned in the previous section, in this paper 6 case studies are performed in the MATLAB platform on 69 bus RDS. The obtained results are discussed in this section. In case 1 , simulations are performed without NR as well as DG and D-STATCOM allocation. In this case, all the tie-switches are opened, i.e., without NR, the obtained power loss is highest and it is $225.041 \mathrm{~kW}$, also the minimum voltage in the entire system is 0.9085 p.u. at bus 65 . In case 2 , the simulations are executed by considering only the NR tool, which resulted in the opened tieswitches of $69,70,14,56$, and 61 . The obtained results have lower power of $99.265 \mathrm{~kW}$ and an improved voltage profile (with a minimum voltage of 0.9419 p.u. at bus 62) compared to case 1 . The power losses obtained in case 2 are $55.89 \%$ lower compared to case 1 . In case 3 , simulations are performed by using the proposed solution methodology by allocating the DG units alone. Here, 3 DG units are allocated with a total capacity of $2320 \mathrm{~kW}$ and hence the obtained power losses are reduced from 225.041 $\mathrm{kW}$ (base case/case 1) to $82.611 \mathrm{~kW}$. This has 1564 resulted in a $63.29 \%$ reduction of power losses and improved voltage profile of the entire system with a minimum voltage of 0.9637 p.u. at bus 65 when compared to case 1 .

In case 4, the proposed methodology has been implemented by considering the NR along with DG allocation and this has resulted in power losses of $41.605 \mathrm{~kW}$ and improved voltage profile of the entire system (with a minimum voltage of 0.979 p.u. at bus 64) compared to cases 1,2 and 3 . In case 5, simulations are performed by including the NR and by optimally allocating the D-STATCOM in the RDS. The minimum losses obtained in this case are $80.085 \mathrm{~kW}$ which is better than the losses obtained from cases 1, 2, and 3. In case 6 , simulations are performed by considering the NR along with simultaneous DG and D-STATCOM allocation. The results obtained in this case are better compared to cases 1 to 5 . The minimum loss obtained is 38.429 $\mathrm{kW}$ which is $82.92 \%$ less compared to base case/case 1. The voltage profile of the entire system has improved with the minimum voltage of 0.9805 p.u. at bus 65 . From the above results and discussion, it can be concluded that the proposed methodology has resulted in minimum power losses and improved voltage profile in the entire RDS. 


\subsection{Limitations}

In this work, DEA has been implemented for solving the DG and D-STATCOM allocation along with the NR problem on the IEEE-69 bus system, but a limitation can be its implementation in a practical distribution system. Certain types of DG units such as wind and solar powers can be analyzed and their uncertainty in output power generation can be modeled by using a probabilistic based approach. Another limitation can be modeling and analysis of the proposed approach for a period of one year and the calculation of performance indices and their impact based on the available geographical data by considering seasonally varying timely load demand, wind, and solar PV powers. The environmental, technical, and economic benefits need to be assessed through the optimal allocation of various components of practical distribution systems. These limitations can be handled in future research work.

\section{Conclusion and future work}

Optimal operation and planning of any distribution system are of importance to ensure that the performance of RDS needs to meet the expected power quality, power loss reduction, voltage stability, and reliability. This paper proposes an approach for optimal operation of RDS with different combinations of NR, DG, and D-STATCOM integration for minimizing the power losses in the system. The objective of this paper is to minimize the loss minimization in the distribution system by simultaneously allocating the DG units, shunt capacitors, and D-STATCOM as well as NR. The proposed problem is solved by using the DEA. Various simulation studies are performed on IEEE 69 bus RDS. The obtained results reveal that by simultaneous allocation of DG and D-STATCOM units along with NR reduction of $82.92 \%$ in power losses when compared to the system with base case configuration. And also, by applying the proposed approach the minimum voltage in the system has been increased to 0.9805 p.u. from 0.9085 p.u. All results obtained in this research work are encouraging, and it can be further extended by integrating the electric vehicles for auxiliary support and voltage profile enhancement. The proposed optimal allocation approach can also be extended for the large-scale integration of renewable sources for active and reactive power support through the effective coordination of protective devices.

\section{Acknowledgment}

This research work was funded by "Woosong University's Academic Research Funding -2021”.
Conflicts of interest

The authors have no conflicts of interest to declare.

\section{References}

[1] Peponis GJ, Papadopoulos MP, Hatziargyriou ND. Distribution network reconfiguration to minimize resistive line losses. IEEE Transactions on Power Delivery. 1995; 10(3):1338-42.

[2] Pamshetti VB, Singh S, Singh SP. Combined impact of network reconfiguration and volt-var control devices on energy savings in the presence of distributed generation. IEEE Systems Journal. 2019; 14(1):995-1006.

[3] Thiruvenkadam S, Kim HJ, Ra IH. Optimal sizing and location identification of suitable compensator in a radial distribution network through fuzzy-flower pollination optimization algorithm. In international conference on inventive computation technologies 2020 (pp. 576-83). IEEE.

[4] Liu Y, Li J, Wu L. Coordinated optimal network reconfiguration and voltage regulator/DER control for unbalanced distribution systems. IEEE Transactions on Smart Grid. 2018; 10(3):2912-22.

[5] Prasad K, Ranjan R, Sahoo NC, Chaturvedi A. Optimal reconfiguration of radial distribution systems using a fuzzy mutated genetic algorithm. IEEE Transactions on Power Delivery. 2005; 20(2):1211-3.

[6] Thukaram DH, Banda HW, Jerome J. A robust three phase power flow algorithm for radial distribution systems. Electric Power Systems Research. 1999; 50(3):227-36.

[7] Salkuti SR. Optimal location and sizing of shunt capacitors with distributed generation in distribution systems. ECTI Transactions on Electrical Engineering, Electronics, and Communications. 2021; 19(1):34-42.

[8] Sambaiah KS, Jayabarathi T. Loss minimization techniques for optimal operation and planning of distribution systems: a review of different methodologies. International Transactions on Electrical Energy Systems. 2020; 30(2).

[9] Leghari ZH, Hassan MY, Said DM, Memon ZA, Hussain S. An efficient framework for integrating distributed generation and capacitor units for simultaneous grid- connected and islanded network operations. International Journal of Energy Research. 2021; 45(10):14920-58.

[10] Kanwar N, Gupta N, Niazi KR, Swarnkar A. Impact of optimal scheduling of DRs and network reconfiguration on the performance of active distribution systems. In India international conference on power electronics 2018 (pp. 1-6). IEEE.

[11] Al SM, Mokhlis H, Mansor NN, Mohamad H, Suyono H, Sapari NM. Fast optimal network reconfiguration with guided initialization based on a simplified network approach. IEEE Access. 2020; 8:11948-63.

[12] Muhammad MA, Mokhlis H, Naidu K, Amin A, Franco JF, Othman M. Distribution network planning enhancement via network reconfiguration and DG integration using dataset approach and water cycle 
algorithm. Journal of Modern Power Systems and Clean Energy. 2019; 8(1):86-93.

[13] Zhan J, Liu W, Chung CY, Yang J. Switch opening and exchange method for stochastic distribution network reconfiguration. IEEE Transactions on Smart Grid. 2020; 11(4):2995-3007.

[14] Lee C, Liu C, Mehrotra S, Bie Z. Robust distribution network reconfiguration. IEEE Transactions on Smart Grid. 2014; 6(2):836-42.

[15] Cui Z, Bai X, Li P, Li B, Cheng J, Su X, et al. Optimal strategies for distribution network reconfiguration considering uncertain wind power. CSEE Journal of Power and Energy Systems. 2020; 6(3):662-71.

[16] Tolabi HB, Ali MH, Rizwan M. Simultaneous reconfiguration, optimal placement of DSTATCOM, and photovoltaic array in a distribution system based on fuzzy-ACO approach. IEEE Transactions on Sustainable Energy. 2014; 6(1):210-8.

[17] Peng Q, Tang Y, Low SH. Feeder reconfiguration in distribution networks based on convex relaxation of OPF. IEEE Transactions on Power Systems. 2014; 30(4):1793-804.

[18] Magadum RB, Kulkarni DB. Power loss minimization of RDN's with network reconfiguration and capacitor. In international conference on communication and signal processing 2020 (pp. 1506-10). IEEE.

[19] Gallano RJ, Nerves AC. Multi-objective optimization of distribution network reconfiguration with capacitor and distributed generator placement. In TENCON 2014-2014 region 10 conference 2014 (pp. 1-6). IEEE.

[20] Ajaja A, Galiana FD. Optimal reconfiguration of distribution networks using MILP and supporting hyperplanes (HYPER). In power \& energy society general meeting 2013 (pp. 1-5). IEEE.

[21] Gomes FV, Carneiro S, Pereira JL, Vinagre MP, Garcia PA, De ALR. A new distribution system reconfiguration approach using optimum power flow and sensitivity analysis for loss reduction. IEEE Transactions on Power Systems. 2006; 21(4):1616-23.

[22] Salkuti SR. Optimal allocation of DG and DSTATCOM in a distribution system using evolutionary based bat algorithm. International Journal of Advanced Computer Science and Applications. 2021; 12(4):360-5.

[23] Rao RS, Narasimham SV, Raju MR, Rao AS. Optimal network reconfiguration of large-scale distribution system using harmony search algorithm. IEEE Transactions on Power Systems. 2010; 26(3):1080-8.

[24] Salkuti SR. Feeder reconfiguration in unbalanced distribution system with wind and solar generation using ant lion optimization. International Journal of Advanced Computer Science and Applications. 2021; 12(3):31-9.

[25] Peponis GJ, Papadopulos MP, Hatziargyriou ND. Optimal operation of distribution networks. IEEE Transactions on Power Systems. 1996; 11(1):59-67.

[26] Biswas PP, Suganthan PN, Amaratunga GA. Distribution network reconfiguration together with distributed generator and shunt capacitor allocation for loss minimization. In congress on evolutionary computation 2018 (pp. 1-7). IEEE.

[27] Salkuti SR. Multi-objective based optimal network reconfiguration using crow search algorithm. International Journal of Advanced Computer Science and Applications. 2021; 12(3): 86-95.

[28] Swarnkar A, Gupta N, Niazi KR. Optimal placement of fixed and switched shunt capacitors for large-scale distribution systems using genetic algorithms. In PES innovative smart grid technologies conference Europe 2010 (pp. 1-8). IEEE.

[29] Ding F, Loparo KA. Feeder reconfiguration for unbalanced distribution systems with distributed generation: a hierarchical decentralized approach. IEEE Transactions on Power Systems. 2015; 31(2):1633-42.

[30] Raut U, Mishra S. Enhanced sine-cosine algorithm for optimal planning of distribution network by incorporating network reconfiguration and distributed generation. Arabian Journal for Science and Engineering. 2021; 46(2):1029-51.

[31] Badran O, Mekhilef S, Mokhlis H, Dahalan W. Optimal reconfiguration of distribution system connected with distributed generations: a review of different methodologies. Renewable and Sustainable Energy Reviews. 2017; 73:854-67.

[32] Buhari M, Levi V, Kapetanaki A. Cable replacement considering optimal wind integration and network reconfiguration. IEEE Transactions on Smart Grid. 2017; 9(6):5752-63.

[33] Scenna F, Anaut D, Passoni LI, Meschino GJ. Reconfiguration of electrical networks by an ant colony optimization algorithm. IEEE Latin America Transactions. 2013; 11(1):538-44.

[34] Esmaeilian HR, Fadaeinedjad R. Optimal reconfiguration and capacitor allocation in unbalanced distribution network considering power quality issues. In international conference and exhibition on electricity distribution. 2013 (pp. 1-4).

[35] Fu YY, Chiang HD. Toward optimal multiperiod network reconfiguration for increasing the hosting capacity of distribution networks. IEEE Transactions on Power Delivery. 2018; 33(5):2294-304.

[36] Kumawat M, Gupta N, Jain N, Bansal RC. Optimal planning of distributed energy resources in harmonics polluted distribution system. Swarm and Evolutionary Computation. 2018; 39:99-113.

[37] Shaheen A, Elsayed A, Ginidi A, El-sehiemy R, Elattar E. Reconfiguration of electrical distribution network-based DG and capacitors allocations using artificial ecosystem optimizer: practical case study. Alexandria Engineering Journal. 2021.

[38] Shaik MA, Mareddy PL, Visali N. Enhancement of voltage profile in the distribution system by reconfiguring with DG placement using equilibrium optimizer. Alexandria Engineering Journal. 2021; 61(5):4081-93.

[39] Veerasamy V, Wahab NI, Ramachandran R, Othman ML, Hizam H, Devendran VS, et al. Recurrent network based power flow solution for voltage 
stability assessment and improvement with distributed energy sources. Applied Energy. 2021.

[40] Kayal P, Chanda CK. Placement of wind and solar based DGs in distribution system for power loss minimization and voltage stability improvement. International Journal of Electrical Power \& Energy Systems. 2013; 53:795-809.

[41] Sultana B, Mustafa MW, Sultana U, Bhatti AR. Review on reliability improvement and power loss reduction in distribution system via network reconfiguration. Renewable and Sustainable Energy Reviews. 2016; 66:297-310.

[42] Raut U, Mishra S. An improved sine-cosine algorithm for simultaneous network reconfiguration and DG allocation in power distribution systems. Applied Soft Computing. 2020.

[43] Altun T, Madani R, Yadav AP, Nasir A, Davoudi A. Optimal reconfiguration of DC networks. IEEE Transactions on Power Systems. 2020; 35(6):4272-84.

[44] Savier JS, Das D. Impact of network reconfiguration on loss allocation of radial distribution systems. IEEE Transactions on Power Delivery. 2007; 22(4):2473-80.

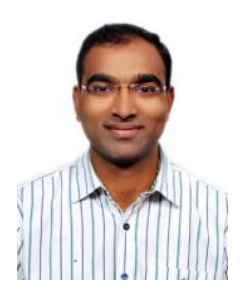

Surender Reddy Salkuti received the M.Tech and Ph.D. degrees in electrical engineering from NIT Warangal and IIT Delhi, New Delhi, India, in 2009 and 2013 respectively. $\mathrm{He}$ was a Postdoctoral Researcher at Howard University, Washington, DC, USA, from 2013 to 2014 . He is currently working as an Associate Professor in the Department of Railroad and Electrical Engineering, Woosong University, Daejeon, Republic of Korea. His current research interests include Power System Restructuring issues, Ancillary Service Pricing, Real and Reactive Power Pricing, Congestion Management, and Market Clearing, including Renewable Energy Sources, Demand Response, Smart Grid Development with Integration of Wind and Solar Photovoltaic Energy Sources, Battery Storage and Electric Vehicles, Artificial Intelligence Applications in Power Systems, and Power System Analysis and Optimization. Email: surender@wsu.ac.kr

\begin{tabular}{lll}
\multicolumn{2}{l}{ Appendix I } \\
\hline S. No. & Abbreviation & Description \\
\hline 1 & ACO & Ant Colony Optimization \\
\hline 2 & AI & Artificial Intelligence \\
\hline 3 & DEA & Differential Evolution Algorithm \\
\hline 4 & DG & Distributed Generation \\
\hline 5 & DLF & Distribution Load Flow \\
\hline 6 & D-STATCOM & $\begin{array}{l}\text { Distribution STATic } \\
\text { COMpensator }\end{array}$ \\
\hline 7 & FACTS & $\begin{array}{l}\text { Flexible Alternating Current } \\
\text { Transmission System }\end{array}$ \\
\hline 8 & MILP & $\begin{array}{l}\text { Mixed-Integer Linear } \\
\text { Programming }\end{array}$ \\
\hline 9 & NR & Network Reconfiguration \\
\hline 10 & ONR & Optimal Network \\
& & Reconfiguration \\
\hline 11 & OPF & Optimal Power Flow \\
\hline 12 & PV & Photovoltaic \\
\hline 13 & RDS & Radial Distribution System \\
\hline 14 & SLD & Single Line Diagram \\
\hline 15 & TPL & Total Active Power Loss \\
\hline 16 & TQL & Total reactive power loss \\
\hline 17 & VSC & Voltage Source Converter \\
\hline
\end{tabular}

